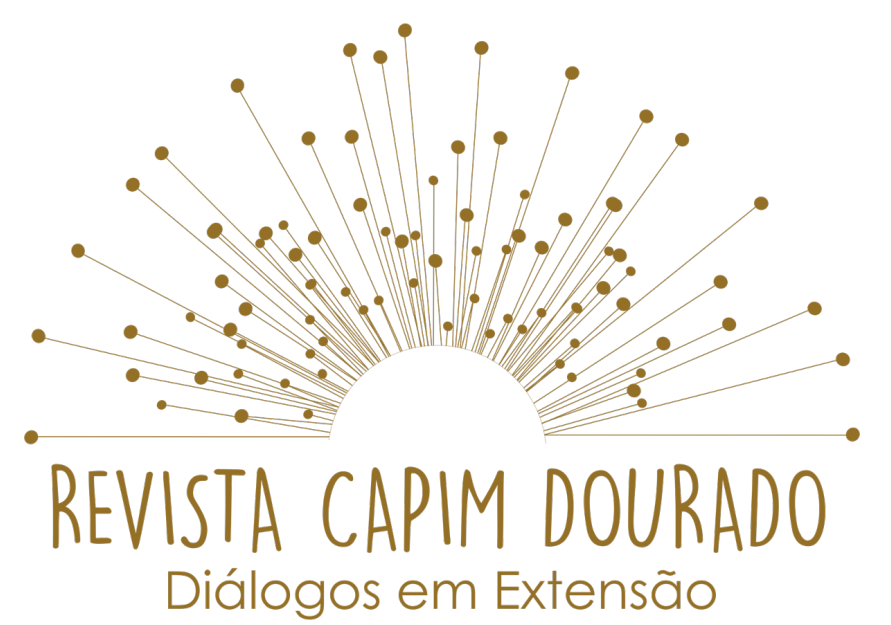

ISSN n² 2595-7341

Vol. 3, n. 1, Janeiro-Abril, 2020

DOI: http://dx.doi.org/10.20873/uft.2595-7341.2020v3n1p12

\title{
PRÁTICAS EXTENSIONISTAS NA UFT: UM FAZER CONTÍNUO DE MUITAS MÃOS E VONTADES
}

A Revista Capim Dourado: Diálogos em Extensão apresenta seu primeiro número de 2020. Os textos que compõem esse número nos ajudam a começar a caminhada e o olhar sobre a extensão na Universidade Federal do Tocantins. Nesse número, o foco serão os relatos de experiência de diversas práticas. Esses estão em espaços e momentos diferentes, demonstrando a riqueza do que a Extensão vem desenvolvendo dentro da UFT.

Na seção RELATO DE EXPERIÊNCIAS, temos o relato intitulado PROJETO UFT ALÉM DOS MUROS, de Dhayna Oliveira Sobral, Kamila Veloso Silva, Luiz Evandro de Melo Junior, Evandro de Luiz, Tábitha Bueno Akemi Ogawa e Abraham Giraldo Damian Zuniga que discutem o Programa de Educação Tutorial (PET) de Engenharia de Alimentos da Universidade Federal do Tocantins que tem como um dos objetivos realizar atividades de extensão que possam integrar o meio acadêmico com a comunidade externa. Um dos projetos é a consultoria que está sendo realizada no Lar Batista F.F. Soren. Esse projeto consiste em aplicar o conhecimento técnico de boas práticas de manipulação e controle de qualidade a fim de evitar desperdícios e contaminação. A ideia foi originada com interesse em proporcionar essa oportunidade para essa instituição filantrópica localizada em Luzimangues distrito de Porto Nacional-TO, uma vez que se trata de uma instituição sem fins lucrativos como forma de colocar em prática os 


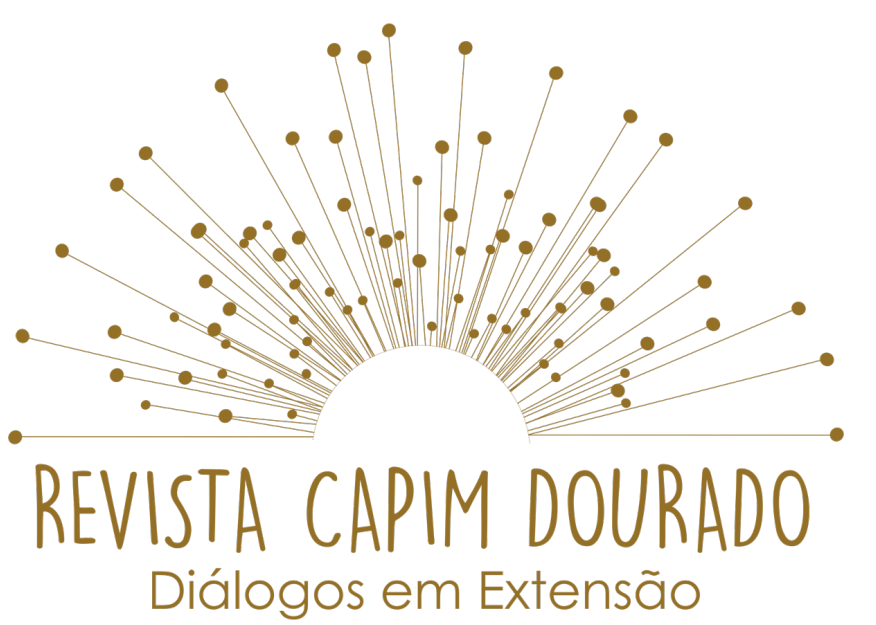

ISSN n² 2595-7341

Vol. 3, n. 1, Janeiro-Abril, 2020

DOI: http://dx.doi.org/10.20873/uft.2595-7341.2020v3n1p12

conhecimentos adquiridos durante o curso ajudando quem precisa. O projeto foi bem aceito, trazendo uma grande realização para o grupo, foi decido que o projeto terá continuidade, podendo ser realizado em longo prazo e com viabilidade para outros.

O relato intitulado PROMOÇÃO DE PRÁTICAS ALIMENTARES SAUDÁVEIS PARA IDOSOS MATRICULADOS NA UNIVERSIDADE DA MATURIDADE, dOS autores Samara Vanderlley Costa Matos, Isabela Cêa, Luiz Sinésio Silva Neto, Daniella Pires Nunes, Fabiane Aparecida Canaan Rezende Rezende destacam que a população idosa vem crescendo de forma significativa, seguindo a tendência mundial de alargamento do topo da pirâmide. Tendo em vista esse envelhecimento da população buscar lo de uma forma saudável e minimizar impactos que o avançar da idade pode trazer são propósitos de idosos que buscam a qualidade de vida. O objetivo deste trabalho foi promover ações de educação alimentar e nutricional (EAN), levando ao conhecimento e empoderamento no que se refere a alimentação, com questões críticas e reflexivas. Os procedimentos metodológicos utilizados foram atendimento gerontológico através da Avaliação Geriátrica Ampla (AGA), a partir das respostas obtidas com a AGA elaborava se um plano de cuidados individualizado, e ações de educação alimentar e nutricional através de palestras e oficinas. Os resultados encontrados foram de multimorbidade, alto índice de doenças articulares e osteoporose, além da Hipertensão Arterial, o que nos leva a observar a importância da educação alimentar e nutricional na contribuição de evitar o aceleramento de comobidades já existentes e no tratamento de carências nutricionais além de promover a autonomia alimentar dessa população. 


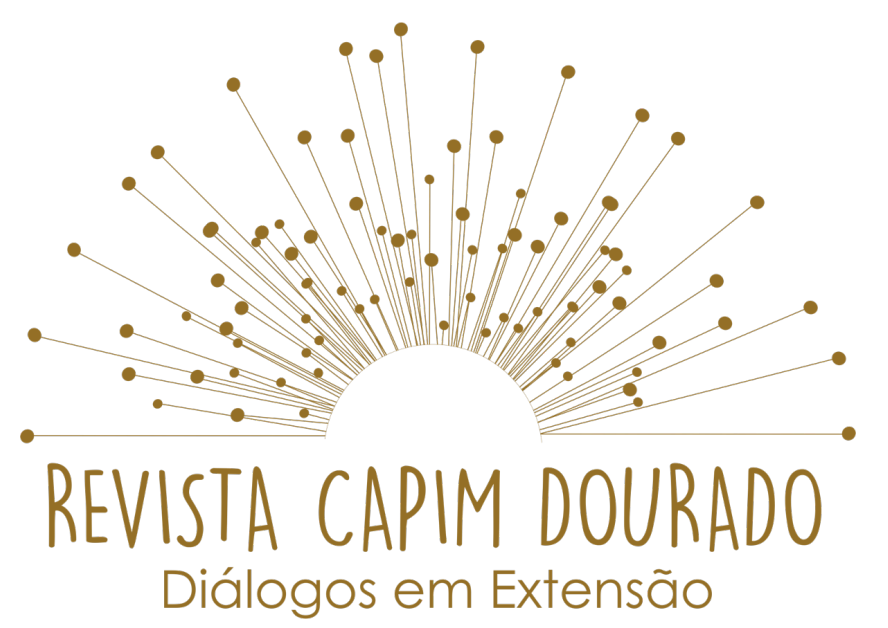

ISSN n² 2595-7341

Vol. 3, n. 1, Janeiro-Abril, 2020

DOI: http://dx.doi.org/10.20873/uft.2595-7341.2020v3n1p12

O relato intitulado PROTAGONISMO ENTRE GERAÇÕES, dos autores Nathália Patrício Leão, Wainesten Camargo Silva, Rodrigo de Sousa Bazzoli, João Aparecido Bazzoli apresentam a ação de extensão os jovens do Centro de Ensino Médio Santa Rita de Cássia propuseram atividade de revitalização do Centro Comunitário Viver com Alegria. Essa ação intergeracional que objetivou promover a melhoria da qualidade de vida de idosos no bairro do Jardim Aureny l/Palmas/Tocantins ao ser concluída provocou efetiva transformação social na comunidade. Foi realizada a revitalização de equipamento público essencial para os idosos, em razão da utilização deste espaço para os seus encontros semanais de dança regional/Forró, uma importante atividade de lazer e cultura. Para além disso, essa ação produziu um efeito simbólico no sentimento de pertencimento local. Sem embargo, o resultado transcendeu a revitalização física predial e urbanística. Tentou-se com a ação, fomentar a dignidade da pessoa humana, o desenvolvimento humano e a garantia dos direitos fundamentais; especialmente por propiciar um espaço de lazer e cultura em bairro periférico, com elevado índice de violência. Para realizar a ação de revitalização foi utilizada a metodologia de tecnologia social, a saber: audiência pública para identificar as demandas e as prioridades da comunidade, devido ao recurso finito; mutirão de serviços de pintura e reformas; parcerias para mão de obra e realização da festa marcando a reinauguração do espaço. Registrou-se, que a demanda comunitária foi atendida integralmente a partir da ação conjugada: escola e comunidade, com apoio do voluntariado e a disponibilização de recursos da iniciativa privada, demonstrando de maneira cabal, que por meio desta tecnologia social foi 


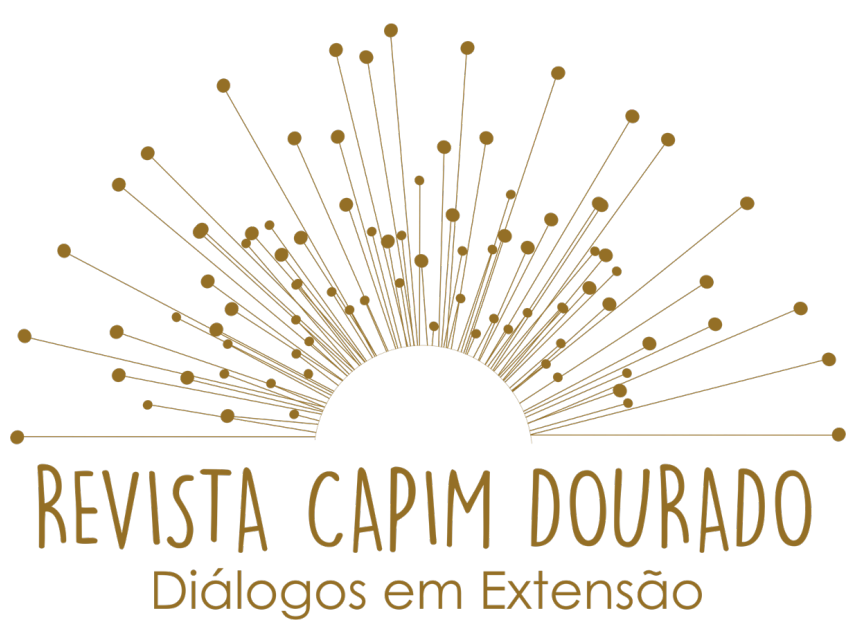

ISSN n² 2595-7341

Vol. 3, n. 1, Janeiro-Abril, 2020

DOI: http://dx.doi.org/10.20873/uft.2595-7341.2020v3n1p12

possível resolver a demanda local, transformando o Nós Propomos em Nós fazemos.

O relato intitulado ARTETERAPIA COM VELHOS: O PAPEL TERAPÊUTICO DA ARTE, dos autores Marcelo Aguiar de Assunção Assunção, Maria de Lourdes Macedo L., Wesquisley Vidal de Santana, Neila Barbosa Osório, Luiz Sinésio Silva Neto apresentam o estudo que objetivou em 2017 oferecer, gratuitamente, cursos de arte e artesanato aos acadêmicos da Universidade da Maturidade e comunidade, objetivando a integração entre velhos e velhas e a melhoria de qualidade de vida. A arte é o bom, criando o belo. A pesquisa é de natureza aplicada, seus objetivos foram exploratórios e os procedimentos técnicos enquadram-se na pesquisa-ação, que é realizada com base na possível solução e discussão de um problema, que envolva de forma coletiva os pesquisados. A arte como terapia teve como resultados melhoria da qualidade de vida e ampliação das relações de afeto entre os acadêmicos da Universidade da maturidade. $O$ projeto teve inicio a partir do desejo dos acadêmicos em realizar atividades artísticas manuais. As reuniões do projeto iniciou em fevereiro de 2017, com um total de 25 participantes. Os resultados alcançado foram: Acadêmicos mais alegres e participativos; Aumento da autoestima e qualidade de vida; Melhoria dos relacionamentos inter-pessoais; Reflexões sobre o aprendizado da arte.

O relato intitulado ESCORPIÕES: UM ESTUDO DE CASO COM ALUNOS DO ENSINO FUNDAMENTAL EM ESCOLAS DOS MUNICÍPIOS DE PORTO NACIONALTO, dos autores Derval Nt Gomes Ribeiro, Yara Gomes Corrêa, Carla Simone Seibert destacam que a educação ambiental pode ajudar na sensibilização da sociedade em relação aos escorpiões, desmistificando a visão antropocêntrica no 


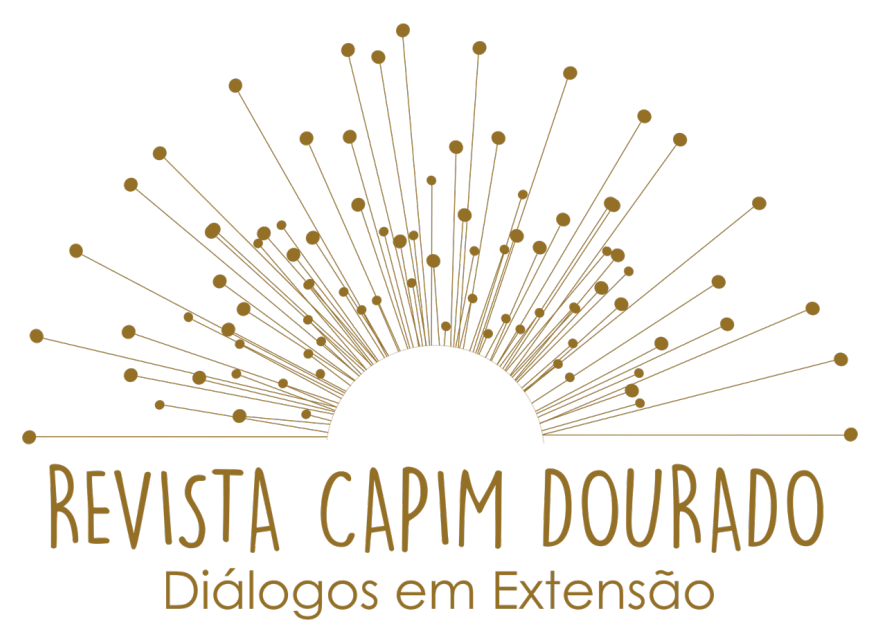

ISSN n² 2595-7341

Vol. 3, n. 1, Janeiro-Abril, 2020

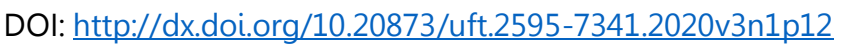

qual o indivíduo se põe acima dos animais não humanos e da natureza, bem como a promover uma interação socioambiental mais justa entre ambos e o ambiente. Conhecer o animal não humano em seu habitat e respeita-lo como tal, pode ajudar na preservação das espécies de escorpião, bem como prevenir acidentes. Para melhorar a relação entre ser humano e animais não humanos, foi desenvolvido um trabalho socioambiental com crianças de 11 a 12 anos, por meio de realização de oficinas com apresentação de materiais didáticos sobre os escorpiões. Foi elaborado um questionário contendo oito questões de fácil interpretação e resposta. As perguntas demonstraram valores significativos de dependência do pós teste em relação a oficina, sendo possível dizer que os sujeitos participantes possuem uma visão convencional acerca dos escorpiões, que pode ser modificada com uma interversão didático-metodológica intencional.

O relato intitulado UFT EM DESTAQUE, dos autores Nathan Alves, André Demarchi destacam a veiculação de informações referentes ao campus de Porto Nacional, da Universidade Federal do Tocantins (UFT) em seu sentido mais lato, por meio de uma plataforma audiovisual, assim obtendo a melhor comunicação e integração da comunidade acadêmica como um todo, bem como pensando em proporcionar o acesso a informações e a vivência universitária para o público externo foi criado o projeto de extensão universitária: UFT em Destaque. O presente projeto seguiu o padrão cinematográfico de produção baseado em uma divisão do trabalho que se ramifica em diversas funções de acordo com a préprodução, gravação e pós-produção, garantindo assim que a periodicidade dos programas, que foram gravados semanalmente e veiculados ao público por meio 


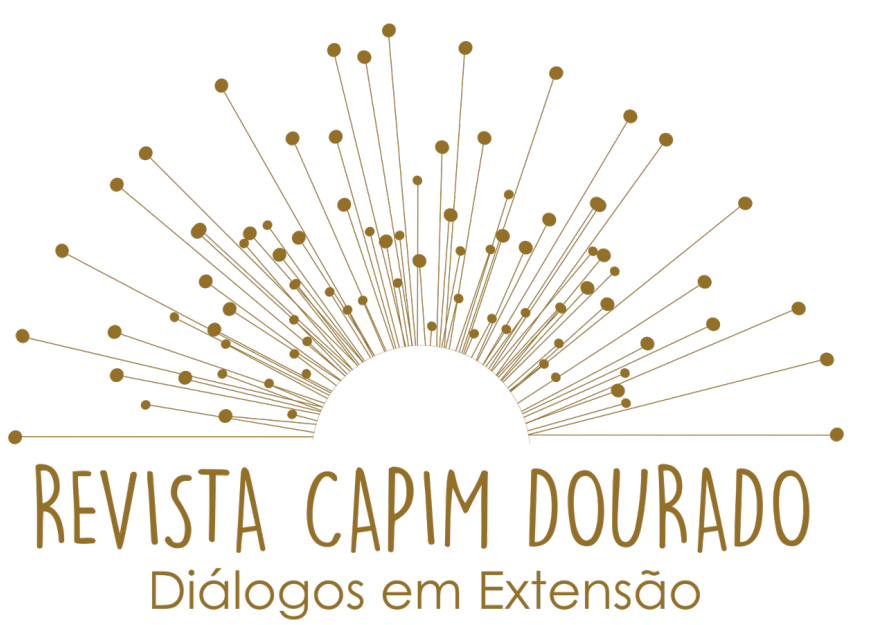

ISSN n² 2595-7341

Vol. 3, n. 1, Janeiro-Abril, 2020

DOI: http://dx.doi.org/10.20873/uft.2595-7341.2020v3n1p12

das redes sociais. A produção destes programas foi feita por alunos de todos os cursos do campus de porto nacional, todos os programas foram traduzidos para a linguagem brasileira de sinais, propiciando também a inclusão social da população usuária dessa linguagem. O projeto conseguiu alcançar seu público alvo (cerca de 1831 visualizações foram alcançadas), proporcionando o acesso às informações acadêmicas e à vivência universitária para o público externo, não apenas discentes, docentes e técnicos pertencentes a UFT, mas também para a comunidade em geral, permitindo que qualquer pessoa com acesso à internet possa visualizar os conteúdos e conhecer a realidade do campus, além de estender as informações sobre a vida universitária do campus de Porto Nacional para a comunidade local e para demais pessoas interessadas.

O relato intitulado CARACTERÍSTICAS SOCIODEMOGRÁFICAS E ESTILO DE VIDA DE ADOLESCENTES DE TOCANTINÓPOLIS/TO, dos autores Helizângela Morais Milhomem, Samuel Carvalho Da Silva, Idelvan Ferreira Da Silva, Sônia Cristina Alves Carvalho Leal, Joana Marcela Sales De Lucena destacam que estudos têm demonstrado que o nível de atividade física está relacionado à manutenção de níveis saudáveis de aptidão física e, baixos níveis de aptidão física têm sido associados a o risco de desenvolver doenças cardiovasculares, de mortalidade por todas as causas, ao tabagismo e ao uso de bebidas alcoólicas. $\mathrm{E}$ tem como descrever a prevalência de atividade física, comportamentos sedentários e suas possíveis associações com os fatores socioeconômicos e antropométricos de escolares da cidade de Tocantinópolis (TO). A coleta incluiu a aplicação de um questionário na forma de entrevista face a face, medida dos comportamentos sedentários considerou a duração (horas por dia) e a frequência 


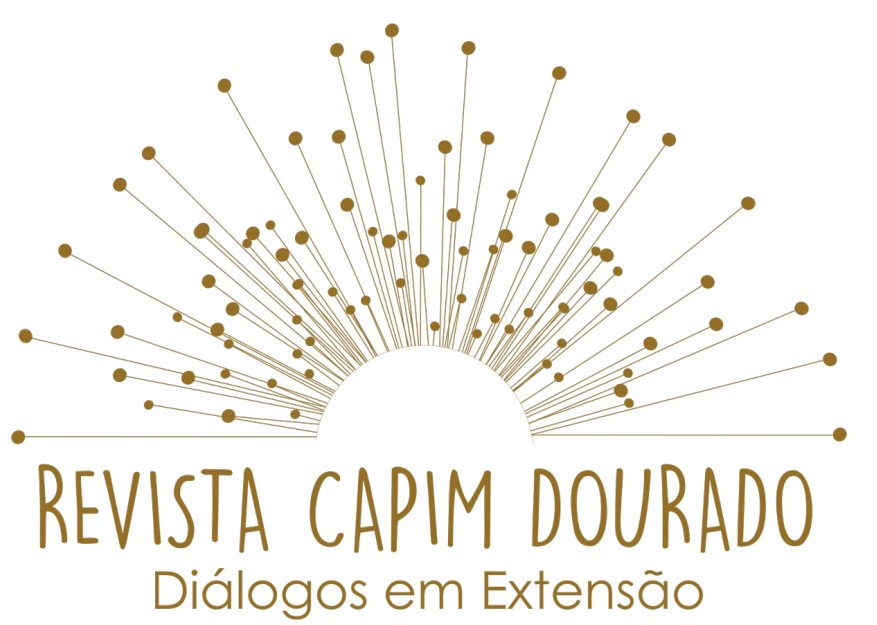

ISSN n² 2595-7341

Vol. 3, n. 1, Janeiro-Abril, 2020

DOI: http://dx.doi.org/10.20873/uft.2595-7341.2020v3n1p12

(quantidade de dias na semana e no fim de semana) do uso, separadamente, de televisão, videogames e computador (no lazer e para atividades adolescentes) em dias de semana e fim de semana, considerando a semana anterior à coleta de dados atividade física foi mensurada por questionário validado Os adolescentes informaram a frequência (dias/semana) duração (minutos/dia) das atividades físicas praticadas na semana anterior à coleta de dados. Participaram do estudo 69 escolares com idade média de 15,4 anos ( $D P=0,2$ ), dos $6^{\circ}$ e $9^{\circ}$ ano do Ensino Fundamental e $1^{\circ}$ e $3^{\circ}$ ensino médio, dos quais $52,2 \%$ eram meninas. Os escolares realizavam em média 256,5 min./dia $(D P=29,9)$ de atividades físicas permaneciam 748,8 min./dia ( $D P=86,5)$ assistindo televisão e 553,6 min./dia (DP $=75,9)$. Os resultados indicam que os adolescentes de Tocantinópolis/TO apresentam pouco tempo de atividade física e altos índices de comportamentos sedentários.

O relato intitulado PREPARAÇÃO DE PEÇAS ANATÔMICAS PARA IMPLEMENTAÇÃO DO MUSEU DE MORFOLOGIA DA UNIVERSIDADE FEDERAL DO TOCANTINS, dos autores Daniel Filipe Lucas Ribeiro, Andressa Diúlia Dantas da Silva, Laura Silva Nascimento, Wallisten Fernandes Souza, Tainá Abreu buscam discorrer sobre os benefícios da implantação de um museu de morfologia na Universidade Federal do Tocantins (UFT), campus Palmas, onde há maior concentração de cursos relacionados as ciências da saúde. O museu universitário torna-se um veículo de transmissão cultural e produção científica. Os alunos recebem capacitação em técnicas anatômicas e são protagonistas no processo de montagem das peças para exposição, utilizando ossos e outros materiais naturais provindos de doação. A presença deste espaço tem como objetivo 


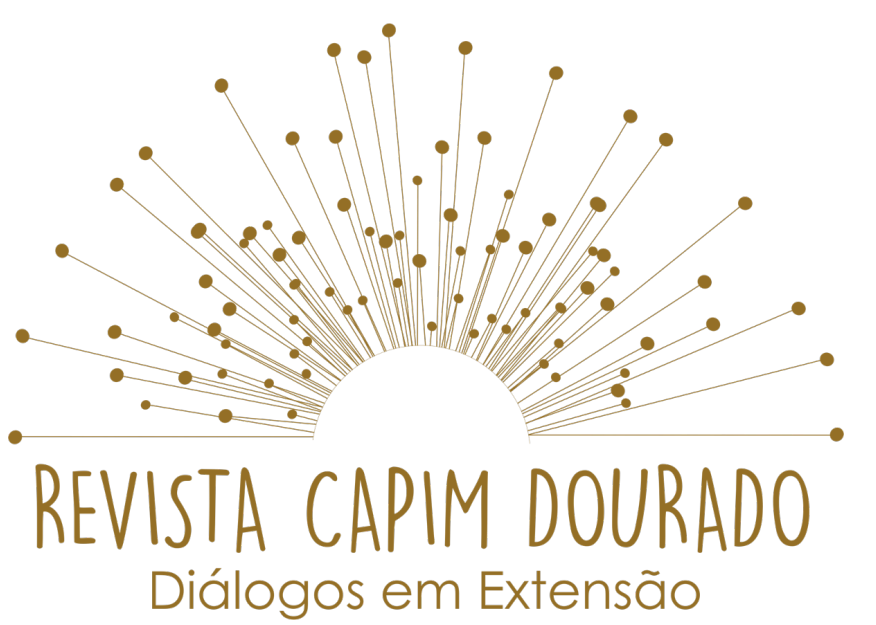

ISSN n² 2595-7341

Vol. 3, n. 1, Janeiro-Abril, 2020

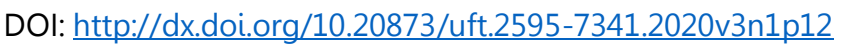

agregar de forma satisfatória na interação entre a comunidade externa e a Universidade, despertar o interesse de educandos do ensino fundamental e médio para cursos da área da saúde através da exposição de estruturas anatômicas, promover maior qualidade e variedade no acervo de peças do laboratório de anatomia, e acarretar em uma formação acadêmica completa para os discentes da UFT.

O relato intitulado OFICINAS DE ORIENTAÇÃO EDUCACIONAL E PROFISSIONAL PARA JOVENS ESTUDANTES DE UMA ESCOLA PÚBLICA, dOS autores Yasmin Coelho dos Santos Parreão, Ladislau Ribeiro do Nascimento relatam uma ação de extensão universitária promovida em uma escola pública localizada em Miracema do Tocantins - TO. Realizamos oficinas de intervenção psicossocial com o intuito de promover práticas de cuidado de si no contexto escolar. Contamos com a participação de um grupo de vinte e três estudantes com histórico de dificuldades de aprendizagem. A intervenção foi desenvolvida em oito encontros semanais, cada um com carga horária de duas horas. As atividades abrangeram rodas de conversa sobre experiências cotidianas, análises coletivas acerca da realidade social, oficinas de artesanato e de Capoeira de Angola, leituras de poesias, e troca de informações sobre áreas de formação e de atuação profissional. Os/as participantes foram mobilizados/as pelo (re)conhecimento de habilidades e competências desenvolvidas ao longo de suas trajetórias escolares.

O relato intitulado RODA DE CONVERSAS COM IDOSOS: O DIÁLOGO COMO TERAPIA, dos autores Carlos Mendes Rosa, Luanna Rodrigues, Luzineide 


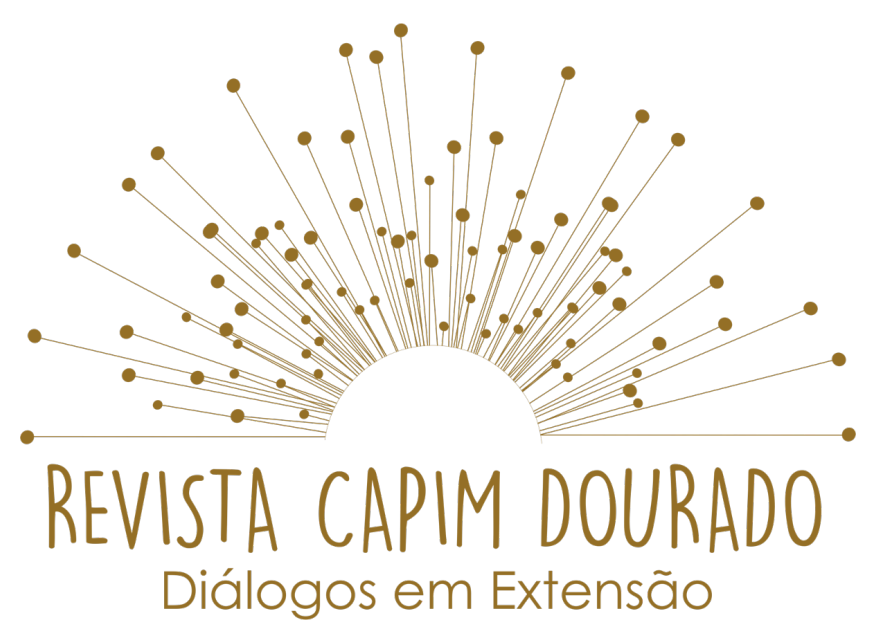

ISSN n² 2595-7341

Vol. 3, n. 1, Janeiro-Abril, 2020

DOI: http://dx.doi.org/10.20873/uft.2595-7341.2020v3n1p12

Rodrigues, Raimundo de Carvalho Lemos, Luara Campos de Lima Costa apresentam o projeto de extensão na área de Psicologia, de natureza integrada e multidisciplinar, possibilitando um melhor entendimento acerca do envelhecimento e seus impactos na subjetividade do indivíduo na contemporaneidade. Entendemos que qualidade de vida na velhice se relaciona a múltiplos fatores como capacidade funcional, estado emocional, interações sociais, atividade intelectual e autoproteção de saúde, além de estabelecerem uma relação direta entre relacionamentos sociais. Nesse sentido, o objetivo do projeto "Roda de Conversas com Idosos" é criar um espaço de fala e partilha de experiências para os idosos dentro da Universidade. O efeito do discurso vigente - modulado pela lógica social do tempo útil que objetos, utensílios eletrônicos e pessoas devem ter, como se tudo tivesse um prazo de validade mais curto na sociedade moderna - tem profundo impacto na economia psíquica dos pacientes velhos, ao ponto dos mesmos afirmarem estar sofrendo de velhice. $O$ termo velhice assume valor de significante, redefinindo a forma de o sujeito conceber a si mesmo e ao seu próprio sofrimento. Por essa razão entende-se como fundamental possibilitar um momento de escuta das vivências subjetivas dos participantes, tematizando questões pertinentes ao universo dos idosos ao longo dos encontros e proporcionando atividades artísticas, culturais e físicas que integram idosos e acadêmicos da universidade.

O relato intitulado COMPARTILHANDO SABERES DA PRÁTICA DOCENTE: O FOCO NA REDAÇÃO, dos autores Ricardo Ferreira de Sousa, Radamés Vieira Nunes apresentam o trabalho desenvolvido para o Programa de Acesso Democrático à Universidade e Apoio Pedagógico ao longo do ano de 2018, 


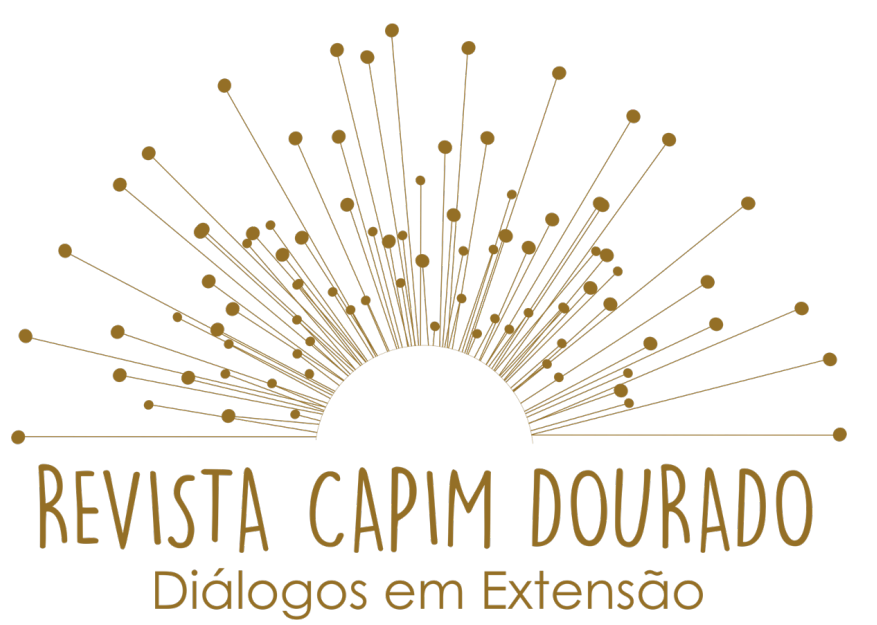

ISSN n² 2595-7341

Vol. 3, n. 1, Janeiro-Abril, 2020

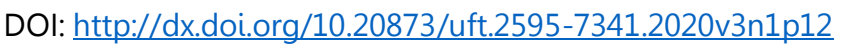

projeto de extensão certificado pela Universidade Federal do Tocantins, campus de Porto Nacional, Tocantins. Aqui, evidenciamos um breve relato de experiência em torno da prática de ensino para o componente curricular de redação. Nosso objetivo é refletir e discutir acerca da importância da monitoria como espaço inicial de formação para a docência, considerando o processo de ensinoaprendizagem e de interação verbal. Nesse intuito, a monitoria é um programa que tem como foco principal, proporcionar que os alunos adquiram experiência na docência, uma vez que os monitores procedem diretamente na prática de ensino em sala de aula. Diante dessa hipótese, o trabalho com a produção textual como foco deste relato, deve ser realizado de forma cuidadosa pelo monitor, pois as estruturas linguístico-textuais nem sempre são assimiladas em tempo hábil pelos alunos, reflexo da pouca prática de leitura e escrita, que levam alguns alunos a cometerem erros ortográficos e gramaticais. Assim, o monitor vem colaborar com o desempenho do ensino e aprendizado - logo que um processo não garante o sucesso do outro -, mediando à comunicação entre os sujeitos envolvidos na disciplina.

O relato intitulado PROGRAMA DE ACESSO DEMOCRÁTICO À UNIVERSIDADE E ACOMPANHAMENTO PEDAGÓGICO - PADU/PORTO NACIONAL 2018, dos autores Ricardo Ferreira de Sousa, Matheus Silva Falcão, Rafael da Silva Lisboa, Wedster Felipe Martins Sabino, Radamés Vieira Nunes reforçam que a extensão universitária é considerada como um dos pilares da educação no Brasil, associando a formação profissional e humanística e também no ensejo da transformação social-político-cultural. O presente relato é fruto de uma ação realizada no Projeto de Extensão Programa de Acesso Democrático à 


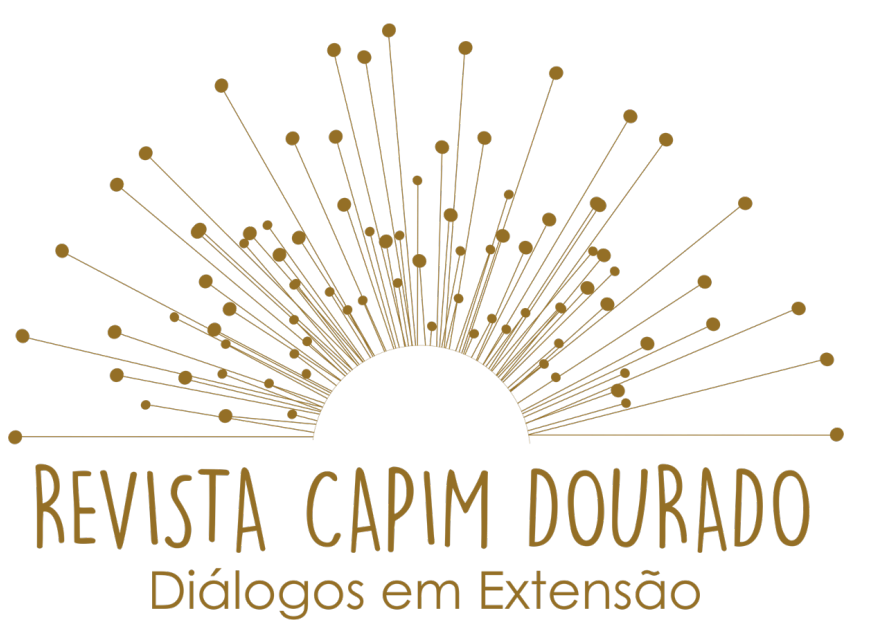

ISSN n² 2595-7341

Vol. 3, n. 1, Janeiro-Abril, 2020

DOI: http://dx.doi.org/10.20873/uft.2595-7341.2020v3n1p12

Universidade e Apoio Pedagógico, vinculado à Universidade Federal do Tocantins, campus universitário de Porto Nacional, estado do Tocantins. A ação consiste no preparo de jovens para as provas do Exame Nacional do Ensino Médio, sendo que os professores ministrantes são acadêmicos de cursos superiores de licenciatura da instituição, no anseio de torna-los de frente e atuante na prática docente, aplicando àquilo que foi apreendido na academia. Diante disso, atuar no projeto de extensão, nos proporciona autoconfiança e conhecimento da prática docente, melhorando o nosso currículo e aumentando as chances para o mercado de trabalho, além de contribuir para desenvolvimento da comunidade, oportunizando a entrada no ensino superior.

O relato intitulado A UNIVERSIDADE ABERTA À COMUNIDADE: CONHECENDO O COMPLEXO DE LABORATÓRIOS DA SAÚDE - CAMPUS DE PALMAS, dos autores Adriane Trindade Gonçalves de Lima, Kércio Jeaneryson Nogueira de Sousa Leite, Aline Queiroz Fernandes, Andressa Diúlia Dantas da Silva, Ediana Vasconcelos Silva apresentam discussões acerca da vivência prática de visitas técnicas realizadas pela demanda externa de estudantes de colônia de férias, ensino fundamental, médio e superior ao complexo de laboratórios da saúde da Universidade Federal do Tocantins (UFT). Ao proporcionar visitas técnicas se estreita as relações entre a comunidade e a universidade ampliando as oportunidades para obtenção de conhecimentos com benefícios mútuos, que é o objetivo do trabalho. Foram confeccionados materiais para apresentação dos métodos de ingresso ao ensino superior, assim como apresentar os cursos ofertados na UFT para tentar despertar o interesse por esta instituição, além disto, a equipe do projeto apresenta os conteúdos nos laboratórios que as escolas 


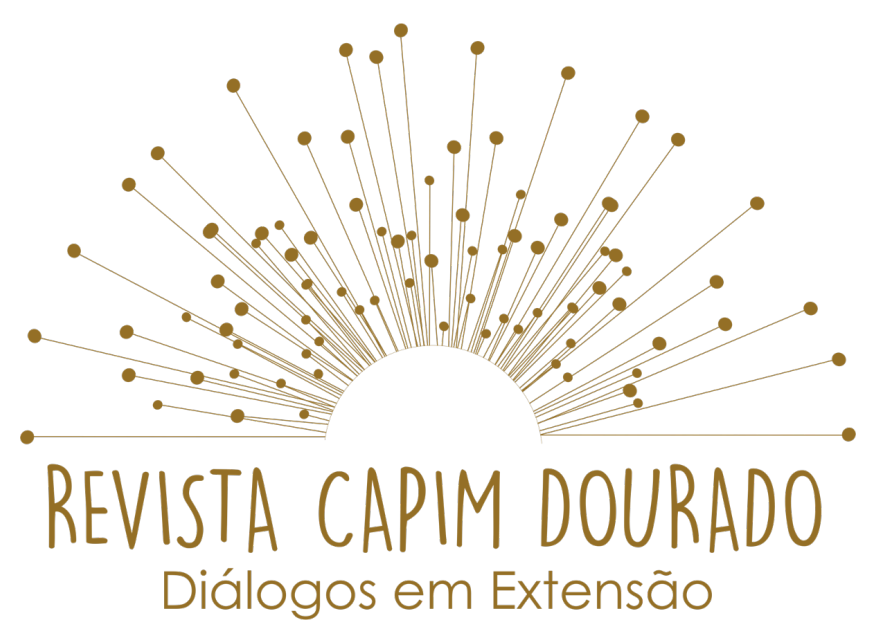

ISSN n² 2595-7341

Vol. 3, n. 1, Janeiro-Abril, 2020

DOI: http://dx.doi.org/10.20873/uft.2595-7341.2020v3n1p12

visam aprofundamento prático. Dessa forma, o projeto teve uma ótima aceitação pública, tanto que, foram recebidas escolas de todo o estado do Tocantins, desde os municípios circunvizinhos aos periféricos, com uma demanda média de três visitas por mês. As experiências vivenciadas pelos extensionistas e colaboradores do projeto além de despertar o interesse pela docência favorece o vínculo com a comunidade externa que é de suma importância para o futuro profissional.

\section{O relato intitulado EXPOR - PALEO: OFICINAS DE CIÊNCIAS BIOLÓGICAS}

PADU-ARAGUAÍNA, dos autores Kassia de Oliveira Madaleno, Antônio Rhamon da Silva Belem, Tatiane Marinho Vieira Tavares, Kênia Gonçalves Costa, José Manoel Sanches da Cruz destacam que durante os finais de semana nos meses de abril a outubro do ano de 2018 na Universidade Federal do Tocantins, campus Araguaína\Cimba, ocorreu as aulas de ciências biológica do cursinho preparatório PADU (Programa de Acesso Democrático a Universidade). A disciplina de ciências biológicas tem como objetivo rever e aprofundar os principais conceitos biológicos cobrado no Exame Nacional do Ensino Médio (ENEM) e preparar o estudante para que esse consiga chegar nas conclusões necessárias para responder tal questionário. De acordo com toda a complexidade que se tem em relação ao estudo de Ciências Biológicas, parte por sua complexidade e parte, por seus conceitos que fogem a realidade do aluno, as aulas de ciências biológicas pretendem diminuir essas barreiras entre estudantes e está ciência. Durante as aulas foi possível observar dificuldade de compreensão de alguns conceitos que são aplicados na disciplina, conceitos quase sempre empregados na paleontologia e geologia, além desse déficit foi possível observa 


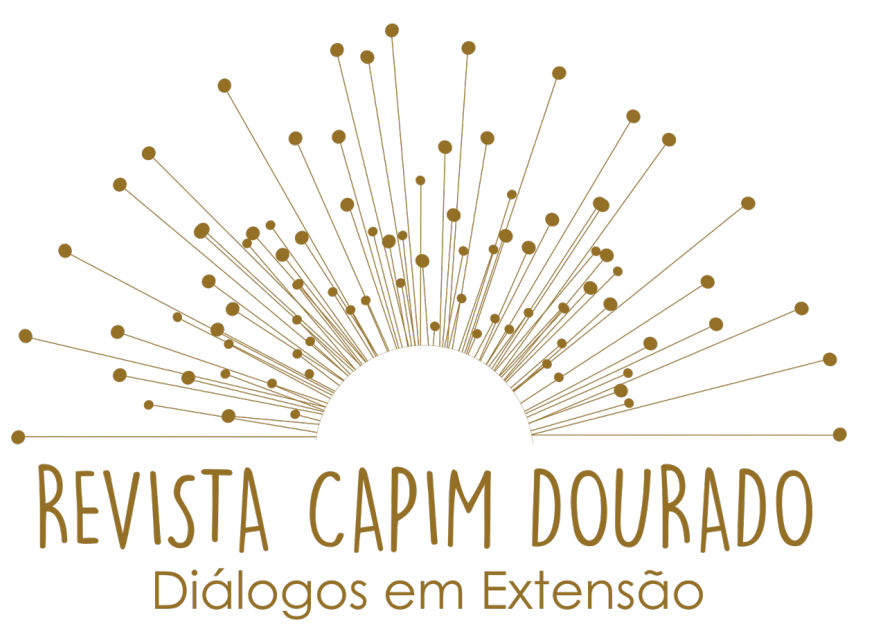

ISSN n² 2595-7341

Vol. 3, n. 1, Janeiro-Abril, 2020

DOI: http://dx.doi.org/10.20873/uft.2595-7341.2020v3n1p12

uma grande curiosidade em relação á fosseis e dinossauros. Com essas observações desenvolvemos uma oficina de exposição paleontologia denominada, Expor-Paleo, pertencente ao projeto intitulado Paleontologia a Caminho da Escola; assim seria ministrada aulas de reforço desses conteúdos de forma didática e atrativa com exposição fósseis e maquetes aos alunos.

O relato intitulado PADU ARAGUAÍNA: experiência do pré-enem comunitário, dos autores Murilo Henrique S. de Paula, Kênia Gonçalves Costa, José Manoel Sanches da Cruz destacam que no objetivo de oferecer oportunidade, democratizando o acesso à universidade através de um projeto voltado para a comunidade estudantil de Araguaína, em março de 2018 teve-se início as atividades letivas do Cursinho pré-enem comunitário, com aulas oferecidas na Universidade Federal do Tocantins, campus de Araguaína, sendo: a) realizados nos finais de semana; b) trabalhando as 4 áreas do conhecimento incluindo redação; c) aulas ministradas pelos próprios acadêmicos da instituição. Com a ideia de procurar parcerias para o material pedagógico a ser seguido, foi fechado uma parceria com o cursinho pré-vestibular "Descomplica", que nos autorizou a utilizar o seu material Enem em 100 dias, que nele contém várias questões divididas por conteúdos que mais caiem no ENEM além de ter o material teórico das 4 áreas de conhecimento. Os resultados foram qualiquantitativos, no qual os números de inscritos para participarem como alunos do projeto, foram 498 , ficando claro a importância desse projeto para a comunidade de Araguaína e com um resultado médio de mais de 80 alunos aprovados no 


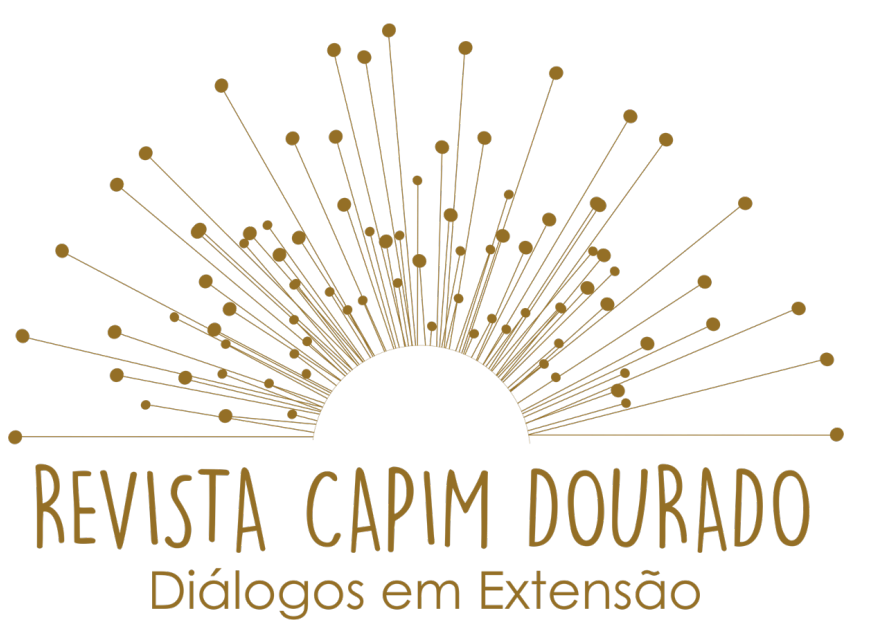

ISSN n² 2595-7341

Vol. 3, n. 1, Janeiro-Abril, 2020

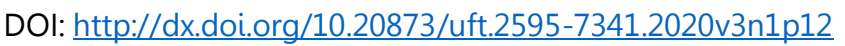

ENEM e vestibulares de instituições de ensino superior, mostrando assim, um resultado satisfatório do projeto final.

O relato intitulado A IMPORTÂNCIA DA PESQUISA E INOVAÇÃO NO JORNALISMO DURANTE A FORMAÇÃO: relato de uma experiência, do autor Clifton Morais Correia apresenta-se a visão de um egresso sobre a importância do curso de Especialização oferecido pelo OPAJE, da Universidade Federal do Tocantins (UFT). O egresso fala de sua trajetória de vida e profissional entrelaçadas com os processos de formação universitária em pesquisa e extensão.

O relato intitulado USO DE PROJETOS INTEGRADORES COMO INSTRUMENTO DE FOMENTO À INOVAÇÃO E INTEGRAÇÃO ENTRE EMPRESAS E ESTUDANTES: Caso CETEC Palmas, dos autores Wellington Rocha Santos, Aron Rodrigo Batista, Francisco Gilson Rebouças Porto Junior apresentam a experiência obtida com o uso de Projetos Integradores nos cursos da Habilitação Técnica e da Aprendizagem Industrial do Centro de Educação e Tecnologia de Palmas. O uso da integração entre teoria e prática implica em garantir a complementaridade que se estabelece entre essas duas dimensões, possibilitando ao aluno aplicar os fundamentos e capacidades em sua prática profissional diária. A integração entre teoria e prática habilita os estudantes a avaliar e explicitar caminhos e alternativas na resolução de problemas, além de possibilitar a transferência das aprendizagens no enfrentamento de situações inusitadas e mais complexas. Sendo assim, os projetos integradores levam os estudantes à geração de novas ideias, que podem se traduzir em produtos (bens ou serviços) com valor agregado. A interação entre estudantes e empresas 


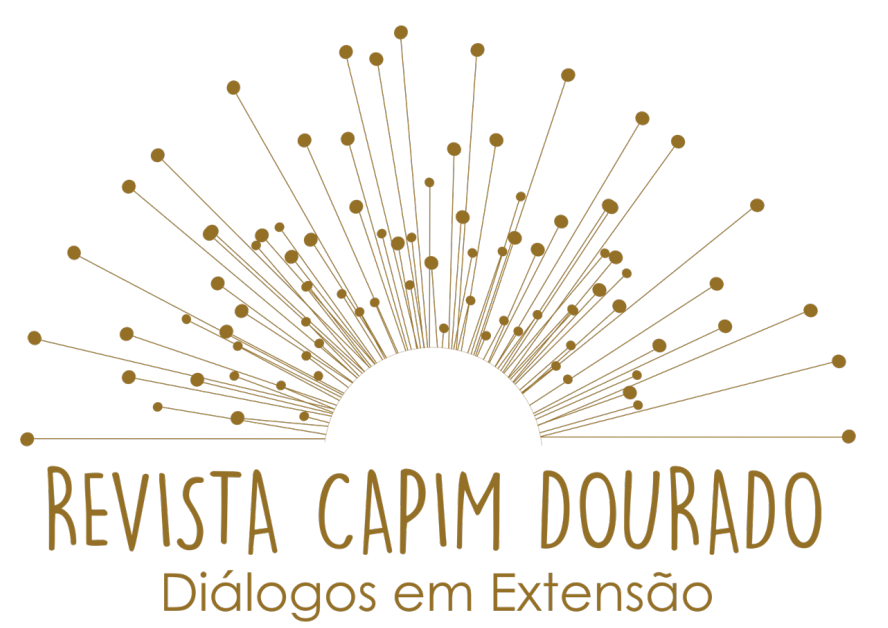

ISSN n² 2595-7341

Vol. 3, n. 1, Janeiro-Abril, 2020

DOI: http://dx.doi.org/10.20873/uft.2595-7341.2020v3n1p12

mobiliza a criatividade, estimulando o livre pensar, o interesse pelo novo, a imaginação e o pensamento prospectivo com o objetivo de lançar o olhar para a inovação. Ao incentivar o pensamento criativo, o uso de projetos em empresas reais oportuniza aprendizagens que vão além da mera reprodução da realidade, propiciando a descoberta de novas perspectivas e de soluções ainda não pensadas.

O relato intitulado INVENTAR COM A DIFERENÇA: uma experiência em Arraias -Tocantins, do autor João Nunes da Silva trata de cinema e teve como objetivo estimular os estudantes da Escola pública a produzirem vídeos e fotografias a partir da realidade. Foram realizadas oficinas com estudantes e professores da Escola Silva Dourado e da UFT Campus de Arraias sobre como ler fotografias e produzir vídeos. O projeto se insere na proposta Inventar com a diferença- Cinema e direitos humanos, tendo como base uma cartilha didática produzida pela Universidade Federal Fluminense. Foram realizadas ao todo 16 oficinas sendo 10 com professores e estudantes da UFT e 6 na Escola. A experiência foi bastante proveitosa para aproximar Universidade e Comunidades escolares bem como para favorecer a reflexão sobre os Direitos Humanos, os quais correspondem, a tudo o que está relacionado a vida humana. O uso do cinema tem sido usado como um recurso fundamental para discutir a vida e suas diferentes nuances, principalmente quando se tratam de Direitos Humanos. $\mathrm{O}$ projeto desenvolvido nas escolas e universidade, conforme pudemos constatar além de aproximar estudantes e professores da prática cinematográfica 


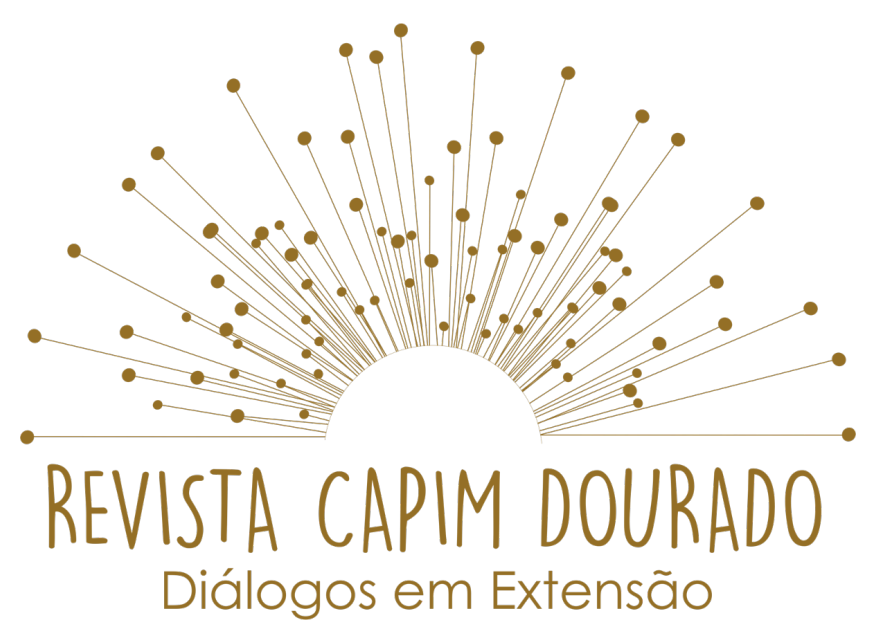

ISSN n² 2595-7341

Vol. 3, n. 1, Janeiro-Abril, 2020

DOI: http://dx.doi.org/10.20873/uft.2595-7341.2020v3n1p12

favoreceu um olhar poético sobre a vida humana e tudo o que a rodeia a partir da realidade.

E finalmente, o relato intitulado A VIOLÊNCIA CULTURAL ESTABELECIDA ENTRE A SOCIEDADE E A COMUNIDADE TRADICIONAL, dos autores Alexandre de Castro Campos, Nelson Russo de Moraes, Raquel Cabral que destacam que as comunidades em geral, e as tradicionais em específico, surgiram no decorrer dos séculos, perdendo seus territórios e sofrendo com a violência cultural imposta pela sociedade, observando a dissolução de suas práticas culturais, traços culturais e crenças em decorrência da fortaleza dos elementos provindos da sociedade, no que the diz respeito de maneira geral traçada no consumo e no individualismo da sociedade que altera a sociabilidade com as comunidades tradicionais que são formadas pela afetividade entre os indivíduos que possuem características próprias na sua organização ocupando e usando os territórios e recursos naturais com condição de desenvolvimento cultural, social e religioso. Dessa forma o trabalho busca abordar de que maneira a violência cultural afeta a sociabilidade entre as comunidades tradicionais e a sociedade através de uma revisão de literatura dos temas sociabilidade, comunidades tradicionais e violência cultural.

Esperamos que a leitura dos artigos e relatos amplie seu olhar sobre as possibilidades da extensão universitária.

Palmas, TO, janeiro de 2020. 


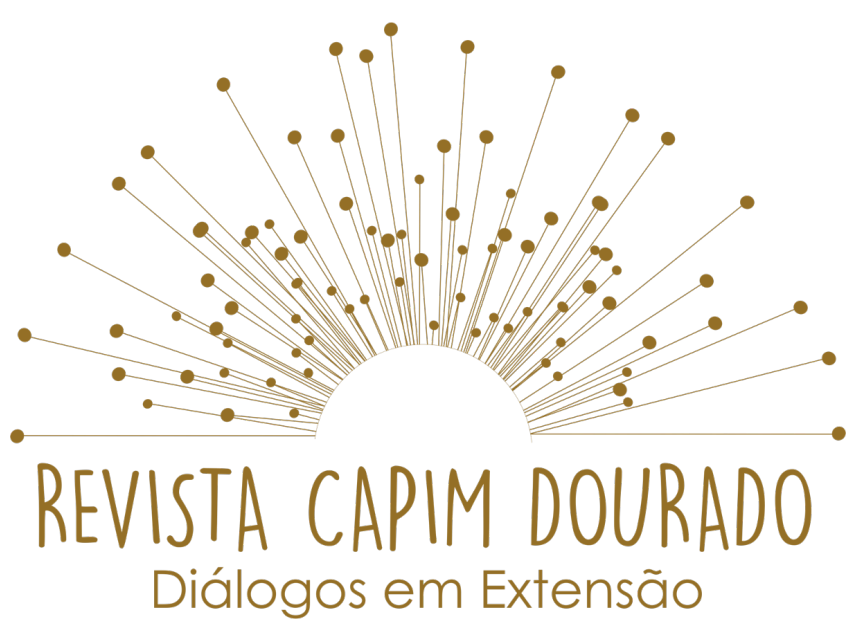

ISSN n² 2595-7341

Vol. 3, n. 1, Janeiro-Abril, 2020

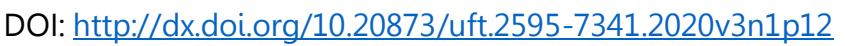

Editor Geral / Chief Editor / Editor general

Prof. Dr. Francisco Gilson Rebouças Porto Junior, Universidade Federal do Tocantins (UFT), Brasil.

Profa. Dra. Vanda Micheli Burginsky, Universidade Federal do Tocantins (UFT),

Brasil.

\section{Referências}

Aguiar de Assunção Assunção , M., Macedo L, M. de L., Vidal de Santana , W., Barbosa Osório , N., \& S. Neto , L. S. (2020). ARTETERAPIA COM VELHOS: O PAPEL TERAPÊUTICO DA ARTE. Capim Dourado: Diálogos Em Extensão, 3(1), 66-75. https://doi.org/10.20873/uft.2595-7341.2020v3n1p66.

Alves, N., \& Demarchi, A. (2020). UFT EM DESTAQUE. Capim Dourado: Diálogos Em Extensão, 3(1), 85-94. https://doi.org/10.20873/uft.2595-7341.2020v3n1p85.

Coelho dos Santos Parreão, Y., \& Ribeiro do Nascimento, L. (2020). OfICINAS DE ORIENTAÇÃO EDUCACIONAL E PROFISSIONAL PARA JOVENS ESTUDANTES DE UMA ESCOLA PÚBLICA. Capim Dourado: Diálogos Em Extensão, 3(1), 111-119. https://doi.org/10.20873/uft.2595-7341.2020v3n1p111.

de Castro Campos, A., Russo de Moraes, N., \& Cabral, R. (2020). A VIOLÊNCIA CULTURAL ESTABELECIDA ENTRE A SOCIEDADE E A COMUNIDADE TRADICIONAL. Capim Dourado: Diálogos Em Extensão, 3(1), 222-235. https://doi.org/10.20873/uft.25957341.2020v3n1p222.

de Oliveira Madaleno, K., Rhamon da Silva Belem, A., Marinho Vieira Tavares, T., Gonçalves Costa , K., \& Sanches da Cruz, J. M. (2020). EXPOR - PALEO: OFICINAS DE CIÊNCIAS BIOLÓGICAS PADU-ARAGUAÍNA. Capim Dourado: Diálogos Em Extensão, 3(1), 161-172. https://doi.org/10.20873/uft.2595-7341.2020v3n1p161.

Ferreira de Sousa, R., Silva Falcão, M., da Silva Lisboa, R., Felipe Martins Sabino, W., \& Vieira Nunes, R. (2020). PROGRAMA DE ACESSO DEMOCRÁTICO À UNIVERSIDADE E 


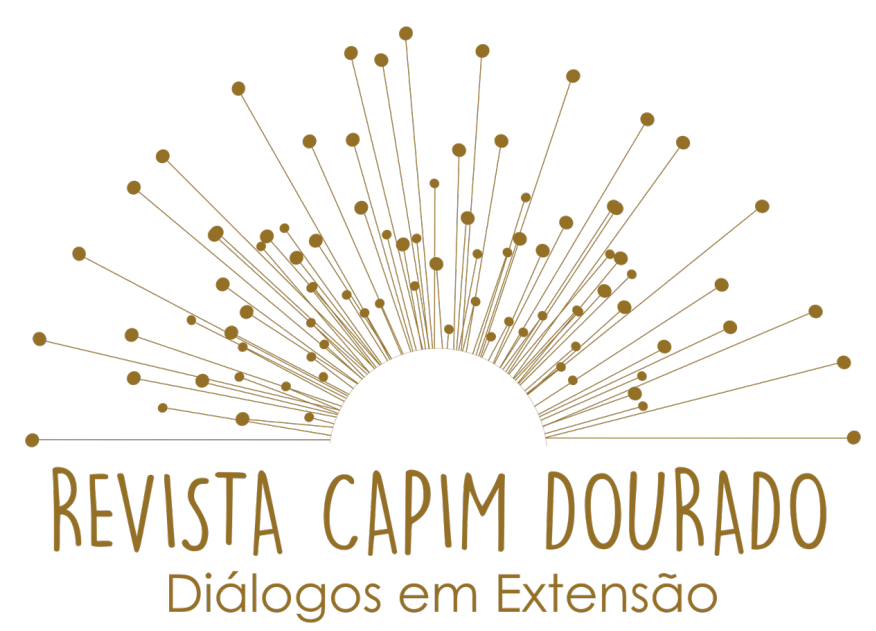

ISSN n² 2595-7341

Vol. 3, n. 1, Janeiro-Abril, 2020

DOI: http://dx.doi.org/10.20873/uft.2595-7341.2020v3n1p12

ACOMPANHAMENTO PEDAGÓGICO - PADU/PORTO NACIONAL 2018. Capim Dourado:

Diálogos Em Extensão, 3(1), 143-150. https://doi.org/10.20873/uft.25957341.2020v3n1p143.

Ferreira de Sousa, R., \& Vieira Nunes, R. (2020). COMPARTILHANDO SABERES DA PRÁTICA DOCENTE: O FOCO NA REDAÇÃO. Capim Dourado: Diálogos Em Extensão, 3(1), 133-142. https://doi.org/10.20873/uft.2595-7341.2020v3n1p133.

Henrique S. de Paula, M., Gonçalves Costa, K., \& Manoel Sanches da Cruz, J. (2020). PADU ARAGUAÍNA: experiência do pré-enem comunitário. Capim Dourado: Diálogos Em Extensão, 3(1), 173-182. https://doi.org/10.20873/uft.2595-7341.2020v3n1p173.

Lucas Ribeiro, D. F., Dantas da Silva, A. D., \& Silva Nascimento, L. (2020). PREPARAÇÃO DE PEÇAS ANATÔMICAS PARA IMPLEMENTAÇÃO DO MUSEU DE MORFOLOGIA DA UNIVERSIDADE FEDERAL DO TOCANTINS. Capim Dourado: Diálogos Em Extensão, 3(1), 103-110. https://doi.org/10.20873/uft.2595-7341.2020v3n1p103.

Mendes Rosa, C., Rodrigues, L., Rodrigues, L., de Carvalho Lemos, R., \& Campos de Lima Costa, L. (2020). RODA DE CONVERSAS COM IDOSOS: O DIÁLOGO COMO TERAPIA. Capim Dourado: Diálogos Em Extensão, 3(1), 120-132. https://doi.org/10.20873/uft.2595-7341.2020v3n1p120.

Morais Correia, C. (2020). A IMPORTÂNCIA DA PESQUISA E INOVAÇÃO NO JORNALISMO DURANTE A FORMAÇÃO: RELATO DE UMA EXPERIÊNCIA . Capim Dourado: Diálogos Em Extensão, 3(1), 183-196. https://doi.org/10.20873/uft.2595-7341.2020v3n1p183.

Morais Milhomem, H., Carvalho Da Silva, S., Ferreira Da Silva, I., Alves Carvalho Leal, S. C., \& Sales De Lucena, J. M. (2020). CARACTERÍSTICAS SOCIODEMOGRÁFICAS E ESTILO DE VIDA DE ADOLESCENTES DE TOCANTINÓPOLIS/TO. Capim Dourado: Diálogos Em Extensão, 3(1), 95-102. https://doi.org/10.20873/uft.2595-7341.2020v3n1p95.

Nt Gomes Ribeiro, D., Gomes Corrêa , Y., \& Simone Seibert , C. (2020). ESCORPIÕES: UM ESTUDO DE CASO COM ALUNOS DO ENSINO FUNDAMENTAL EM ESCOLAS DOS MUNICÍPIOS DE PORTO NACIONAL-TO. Capim Dourado: Diálogos Em Extensão, 3(1), 7684. https://doi.org/10.20873/uft.2595-7341.2020v3n1p76. 


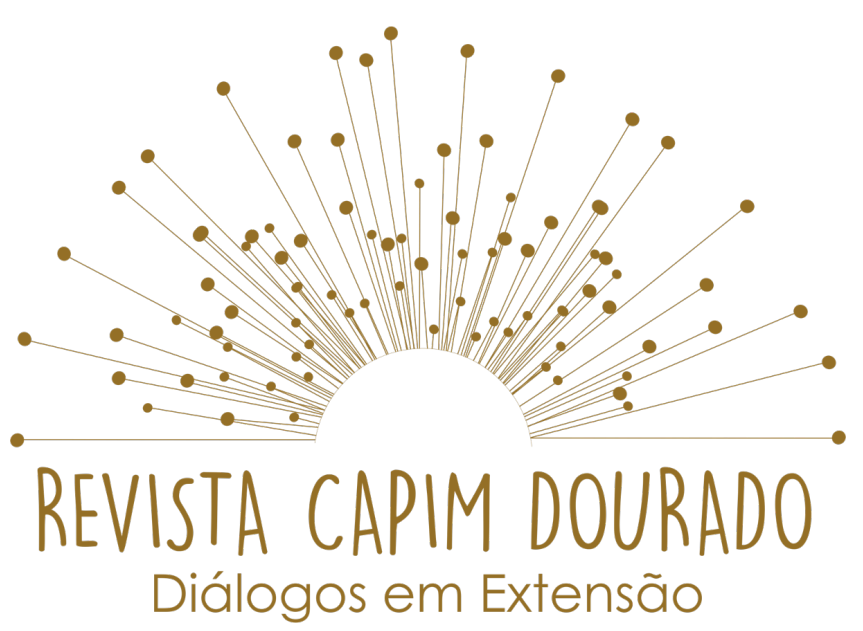

ISSN n² 2595-7341

Vol. 3, n. 1, Janeiro-Abril, 2020

DOI: http://dx.doi.org/10.20873/uft.2595-7341.2020v3n1p12

Nunes da Silva, J. (2020). INVENTAR COM A DIFERENÇA: uma experiência em Arraias Tocantins. Capim Dourado: Diálogos Em Extensão, 3(1), 210-221. https://doi.org/10.20873/uft.2595-7341.2020v3n1p210.

Patrício Leão , N., Camargo Silva , W., de Sousa Bazzoli, R., \& Aparecido Bazzoli , J. (2020). PROTAGONISMO ENTRE GERAÇÕES. Capim Dourado: Diálogos Em Extensão, 3(1), 53-65. https://doi.org/10.20873/uft.2595-7341.2020v3n1p53.

Rocha Santos, W., Rodrigo Batista, A., \& Rebouças Porto Junior, F. G. (2020). USO DE PROJETOS INTEGRADORES COMO INSTRUMENTO DE FOMENTO À INOVAÇÃO E INTEGRAÇÃO ENTRE EMPRESAS E ESTUDANTES: Caso CETEC Palmas . Capim Dourado: Diálogos Em Extensão, 3(1), 197-209. https://doi.org/10.20873/uft.25957341.2020v3n1p197.

Sobral, D. O., Silva, K. V., Melo Junior, L. E. de, Luiz, E. de, Ogawa, T. B. A., \& Zuniga, A. G. D. (2020). PROJETO UFT ALÉM DOS MUROS. Capim Dourado: Diálogos Em Extensão, 3(1), 31-40. https://doi.org/10.20873/uft.2595-7341.2020v3n1p31.

Trindade Gonçalves de Lima, A., Nogueira de Sousa Leite, K. J., Queiroz Fernandes, A., Dantas da Silva, A. D., \& Vasconcelos Silva, E. (2020). A UNIVERSIDADE ABERTA À COMUNIDADE: CONHECENDO O COMPLEXO DE LABORATÓRIOS DA SAÚDE - CAMPUS DE PALMAS. Capim Dourado: Diálogos Em Extensão, 3(1), 151-160. https://doi.org/10.20873/uft.2595-7341.2020v3n1p151.

Vanderlley Costa Matos, S., Cêa , I., Sinésio Silva Neto , L., Pires Nunes, D., \& Canaan Rezende Rezende, F. A. (2020). PROMOÇÃO DE PRÁTICAS ALIMENTARES SAUDÁVEIS PARA IDOSOS MATRICULADOS NA UNIVERSIDADE DA MATURIDADE. Capim Dourado: Diálogos Em Extensão, 3(1), 41-52. https://doi.org/10.20873/uft.25957341.2020v3n1p41. 